\title{
Modeling polar glaciation
}

\author{
Robert J. Oglesby, ${ }^{1}$ Susan Marshall ${ }^{2}$ \\ ${ }^{1}$ Department of Earth and Atmospheric Sciences, Purdue University, West Lafayette, IN 47907, U.S.A. \\ ${ }^{2}$ Department of Geography and Earth Sciences, University of North Carolina, Charlotte, NC 28262, U.S.A.
}

\begin{abstract}
A key measure of our understanding of polar glaciation is the ability to model the initiation, maintenance, and elimination of glaciation over Antarctica and high-latitude land masses in the Northern Hemisphere. Studies that address questions of Cenozoic Antarctic glaciation, as well as studies that address questions of Pleistocene glaciation in the Northern Hemisphere, are described in some detail. The intention is to emphasize and discuss issues that are important in modeling these types of glacial events as much as to present specific results.
\end{abstract}

\section{INTRODUCTION}

Understanding the nature and causes of continental glaciation is of fundamental importance to the study of past Earth climates and possible future climatic change. The geologic record indicates the existence of massive ice sheets over the Northern Hemisphere as recently as 20000 years ago, while ice sheets apparently also existed on different continents hundreds of millions of years ago. The effects of future natural and anthropogenic climatic change on ice sheets are also of more immediate concern, because of such issues as possible rises in sea level if the ice sheets that currently exist shrink back or collapse.

Examples of key questions regarding glaciation include: Why is Antarctica glaciated at present, while we are currently in an interglacial period in the Northern Hemisphere, with ice sheets outside mountain regions restricted to Greenland and the islands of the High Arctic? Was Antarctica largely or completely deglaciated early in the Cenozoic? What are the causes and implications of the massive continental ice sheets over much of Canada, Scandinavia, and Siberia that occurred during the Last Glacial Maximum?

A hierarchy of climate models, ranging from simple energy-balance models (EBMs) to much more complex general circulation models (GCMs) has been applied to the study of polar glaciation. These studies will be reviewed briefly, emphasizing both the methodologies employed and the major implications of the results. Described in more detail are previous studies we have made concerning Antarctic glaciation (Oglesby, 1989, 1991; Marshall and Oglesby, 1994; Verbitsky and Oglesby, 1995), which address questions of Cenozoic Antarctic glaciation and possible behavior under future greenhouse warming. Then discussed are studies that address questions of Pleistocene glaciation in the Northern Hemisphere that emphasize both the effects of ice sheets on climate (Felzer and others, 1996, in press) and the effects of climate on ice sheets (Oglesby, 1990; Verbitsky and Oglesby, 1992; Marshall and Oglesby, 1994).

\section{BASIC CONCEPTS}

The initiation and growth of an ice sheet or large glacier requires a region with a positive net snow accumulation (that is, cold-season snowfall exceeds warm-season snowmelt). Because snow can melt very rapidly, in a practical sense this means that little or no snowmelt should occur in the warm season (mountain glaciers being one possible exception). If enough ice builds in a region with a positive net snow accumulation, the ice can flow into adjoining regions with a negative mass balance. Important feedbacks can also arise between the emerging ice sheet and the overall climate. Many modeling studies have placed an ice sheet as a boundary condition, and inferred whether growth or melt would occur based on the energy balance over the ice sheet. A major difficulty with this approach is that the ice sheet may be inconsistent with other model boundary conditions and forcings. A more physically realistic method is to use the model to compute snow balance, thereby directly determining regions where ice sheets could arise and, in conjunction with models of ice-sheet thermodynamics and dynamics, their characteristics as well. A key problem is that the hydrology models that we use to compute the snow balance (see Marshall and others, 1997) are still very crude.

One can easily envisage a dynamical balance, or equilibrium, with an ice sheet of some considerable size, with the areal extent and mass staying approximately constant in time. The positive-accumulation zone serves as the source, while the negative-accumulation zone serves as a sink, with a balancing transport between the two (through a region of indefinite size assumed to be neutral, and a net annual snow accumulation close to zero).

More generally, we can write an ice-sheet equation schematically as:

$$
\mathrm{d} I / \mathrm{d} t=S A-S M+(\nabla \cdot V I)
$$

where $I$ refers to ice volume, $S A$ to snow accumulation, $S M$ to snowmelt, $V$ is the velocity of ice, and the del-symbol is the del operator (that is, $\nabla \cdot V I$ refers to the divergence of 
flowing ice). For quasi-equilibrium conditions, we require that $\mathrm{d} I / \mathrm{d} t$ be 0 (a dynamical balance is obtained). The assumption of an ice sheet in dynamic equilibrium is probably not a very good one for most actual ice sheets over time periods from a few hundreds to thousands of years. In actuality, ice sheets are probably not very stable (i.e. roughly constant in mass and configuration) for very long. In the introduction, we described three states, or stages, of an ice sheet: initiation, maintenance and elimination. Mathematically, these are equivalent to cases where $\mathrm{d} I / \mathrm{d} t>0$ (ice sheet initiation and growth); $\mathrm{d} I / \mathrm{d} t=0$ (maintenance, i.e. the ice sheet is constant in size) and $\mathrm{d} I<0$ (ice sheet decay and eventual elimination). A comprehensive theory, or model, of continental ice sheets (and hence the "Ice Ages") must account for all three of these states, and how the transitions take place between them within realistic time-scales. Clearly, though, the better we understand each state by itself, the better we will be able to combine them so as to account for entire ice-sheet cycles.

\section{MODELING APPROACHES}

The first question is whether to take an equilibrium or dynamic approach - that is, do we want to model each of the three states as separate entities, or do we want to model how the three combine to form one (or more) full ice-sheet cycles?

If we take the equilibrium modeling approach, we assume we are investigating for a single point in time the boundary conditions, forcings, and/or physical processes responsible for a particular state involving either ice-sheet growth, maintenance (steady-state) or decay. The spatial resolution of the model can range from 0 -dimensional $(0$ D) (global average) to full three-dimensional (3-D) resolution. (Note that if one is simulating the geographic extent of an ice sheet, then at any given time different regions may be in different states. Indeed, for an ice-sheet in quasi-equilibrium, one would expect different portions of the ice sheet to be in each state, such that they approximately balance. Any individual spatial point (gridpoint) must, however, be in one and only one of the three states.) While we may be able to make inferences about how the states interact to make a full cycle, and indeed in some cases even assign possible time-scales, this type of modeling approach does not explicitly solve for the progress of an ice sheet through time.

If we take the dynamical modeling approach, we assume we are investigating entire cycles of ice-sheet growth, maintenance and decay. Each of these states has a particular time-scale attached to it, and the model marches forward in time from the onset of glaciation through the growth and maturation of the ice sheets until they decay back to approximately the original state of little or no ice. Multiple cycles may also be solved for. In principle, the spatial resolution of these models, as in the equilibrium approach, can range from a global average to full 3-D horizontal and vertical resolution. In practice, for a variety of reasons, these models are usually solved either for globally averaged quantities or zonally and vertically averaged quantities (onedimensional resolution). While dynamic models of ice sheets are ultimately required and considerable work has been done in this regard (see review by Saltzman, 1990), because our expertise is largely in equilibrium modeling we will not consider dynamical models any further in this paper.

\section{EQUILIBRIUM GLIMATE MODELING OF ICE SHEETS}

From the point-of-view of equilibrium modeling, we can consider the Southern Hemisphere (specifically Antarctica) as a case for explaining the current existence of an ice sheet or, conversely, answering the (more challenging) question of explaining conditions under which no Antarctic ice sheet would exist. The Northern Hemisphere, on the other hand, represents a case for explaining the current lack of large North American and Eurasian ice sheets (again, presumably accomplished by a model simulation of the presentday climate), or the more difficult problem of explaining the presence of past ice sheets where today there are none.

\section{ANTARGTIC GLACIATION}

Some studies of the Last Glacial Maximum have looked at Southern Hemisphere effects, including implications for the Antarctic ice sheets. Some pre-Pleistocene (e.g. Cretaceous) modeling studies have mentioned implications for high-latitude Southern Hemisphere land masses, though the focus of these studies was elsewhere. In many of these studies it was difficult to obtain or infer the ice-free conditions thought to have existed during the Cretaceous. Crowley and others (1989) have used energy-balance models (EBMs) extensively to look at possible glaciation for Southern Hemisphere land masses, addressing such factors as the size of the continent, and its position relative to the South Pole. These studies are limited by the lack of an explicit hydrologic cycle in the EBM. Crowley and others (1989) came to two major conclusions: (1) the larger the high-latitude land mass, the greater the summer-time heating and the lower the likelihood of glaciation; and (2) a continent centered on the Pole is less likely to have glaciation than one in which the Pole is located near a coast.

Oglesby (1989, 1991) used a GCM (NCAR CCMl, U.S. National Center for Atmospheric Research) to look at explicit factors that might be important in initiating or eliminating Antarctic glaciation, looking at many of the same factors as Crowley and others (1989). Conclusions different from the previous EBM studies were obtained. Oglesby found that sea-surface temperatures (SSTs) and continentality (including the joining of Australia to Antarctica) had relatively minor effects, and that increasing continentality actually increased the likelihood of glaciation by removing regions from the moderating (warming) effect of the ocean. Instead, the largest control was exerted by the topography of Antarctica itself, and the higher the mean elevation of the continent meant the greater the likelihood of glaciation. Since at present the ice sheet itself is the most significant contributor to the elevation of Antarctica, this also implies the importance of elevation feedbacks as the ice sheet grows or shrinks.

Marshall and Oglesby (1994) reassessed these CCM1 results with an improved snow hydrology (see Marshall and others, 1997) and found that because little snowmelt occurred, there were no substantive changes in the results. Figure 1 shows snow cover over Antarctica for a case with present-day topography but with SSTs everywhere above freezing (i.e., no sea ice around Antarctica) and with the standard snow hydrology and the improved snow hydrology of Marshall and Oglesby (1994). Note that even with the warmer conditions, extensive snow exists over all Antarctic 

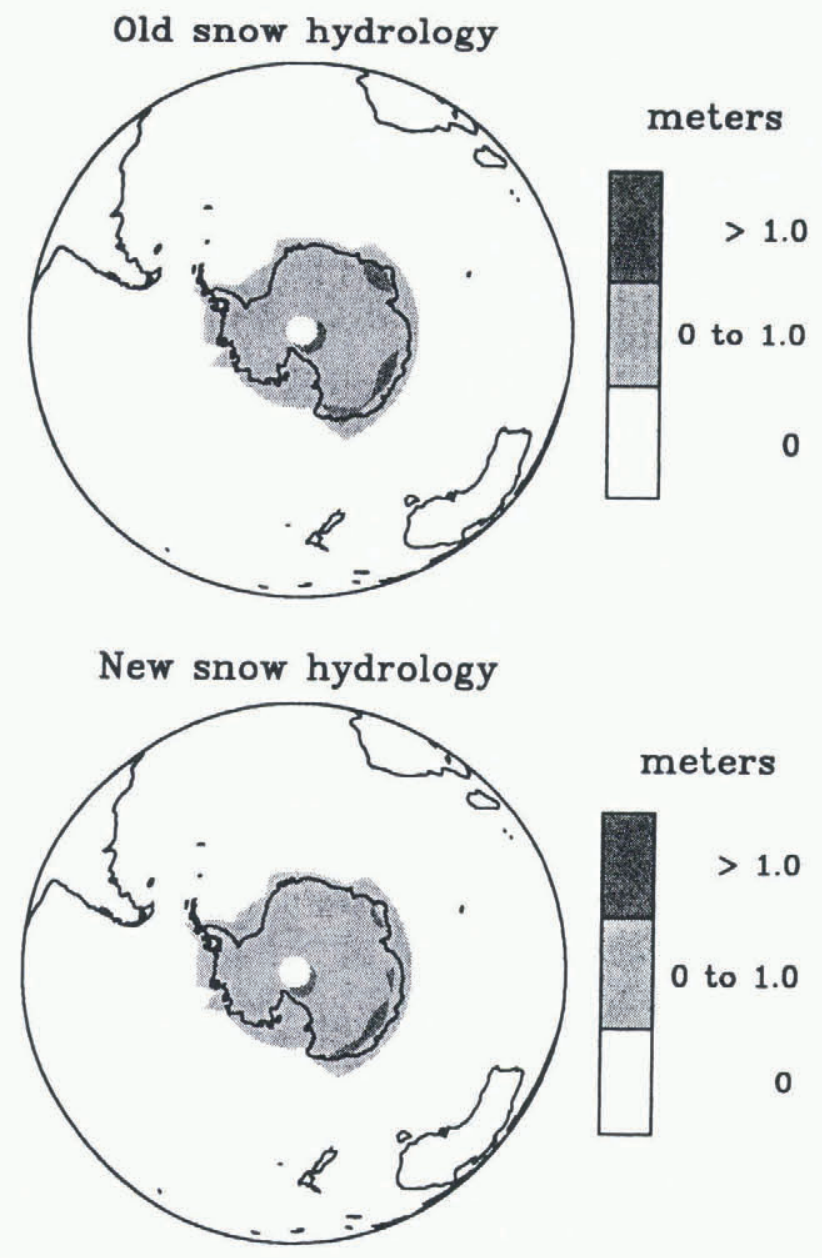

Fig. 1. Snow depth over Antarctica for a CCMI case with present-day geography and topography, but SST warmed by up to $15^{\circ} \mathrm{C}$ and no sea ice. Gray shades are from $0.0-8.0 \mathrm{~m}$ liquid water equivalent.

gridpoints, and furthermore, no significant difference is seen between the old and new snow-hydrology cases.

Oglesby (1989) also found that large changes in atmospheric $\mathrm{CO}_{2}$ had a relatively small impact on Antarctic ice sheets, a result further confirmed by Verbitsky and Oglesby (1995), who used GCM results as input into an ice-sheet model, and then explicitly simulated the growth of resulting ice sheets. Small regions of both increased and decreased ice growth were found with a doubling of $\mathrm{CO}_{2}$, with no indication of a catastrophic collapse of the West Antarctic ice sheet, as has sometimes been suggested with future greenhouse warming.

\section{Northern Hemisphere glaciation}

Prior to about 2.5 Ma according to the geological evidence, the Northern Hemisphere is thought to have been largely or completely ice-free (apart from possible small mountain glaciers). Since then, large ice sheets have waxed and waned over much of the mid- and high-latitude land masses in a quasi-periodic fashion, culminating in the approximately 100 ka glacial cycles of the Late Quaternary. In a climatemodeling context, Northern Hemisphere glaciation can be looked at in two distinct ways: (1) the effects of ice sheets on Northern Hemisphere (and global) climate, in which an ice sheet or ice sheets are imposed as a boundary condition in the climate model, and their impact on atmospheric and/or oceanic climate is determined, and (2) the effects of climate on the ice sheets: that is, how did the ice sheets get there? Why do they go through cycles of advance and retreat?

Many studies, too numerous to mention here, have examined (1), with an emphasis on the Last Glacial Maximum. Less attention has been paid to (2), so our work in this regard is discussed in some detail.

\section{(1) The effects of Northern Hemisphere ice sheets on climate}

One drawback to many, but not all, previous studies is that they included other boundary and condition changes (e.g. solar radiation changes according to Milankovitch, albedo or $\mathrm{CO}_{2}$ in addition to ice sheets. The studies in general found that the ice sheets had a considerable impact on Northern Hemisphere atmospheric circulation and regional temperatures, and on the heat and moisture balance of the ocean. A general global cooling is typically found, but it is not always clear to what extent that is due to the ice sheets.

Felzer and others (1996) systematically examined the effects of ice-sheet size and height on climate, using a series of simulations with the NCAR CCMl, in which ice sheets of varying heights and areas were input, but with all otherwise set to present-day conditions. The results suggest a large local effect, but fairly small downstream effects due to the ice sheets, and that the area of an ice sheet was more important than its height in affecting climate. Felzer and others (in press) used these icc-sheet results, as well as model results pertaining to atmospheric $\mathrm{CO}_{2}$ and orbital insolation changes, to isolate the relative effects of each of the three in modeling the Last Glacial Maximum. At $21 \mathrm{ka}$, ice sheets and reduced atmospheric $\mathrm{CO}_{2}$ had roughly equal effects, but orbital insolation was much more minor (orbital characteristics at this time were not much different than at present).

\section{(2) How do Northern Hemisphere ice sheets come about?}

A number of the GCM studies that focused on the effects of ice sheets on climate noted the energy balance over their imposed ice sheets along with implications for growth or melt of the ice sheet (in virtually every case net melt was inferred). Rind and others (1989) and Oglesby (1990) were probably the first to consider explicitly the initiation of ice sheets in GCMs. Rind and others (1989) imposed small amounts of snow (ice) in regions where Northern Hemisphere ice sheets are though to have initiated and evaluated the surface-energy budgets under a variety of orbital insolation regimes, and inferred whether the ice would melt or grow. Oglesby (1990) took this a step further, and imposed snow cover over all Northern Hemisphere land points in the NCAR CCM1 so that model snow-hydrology processes then explicitly simulated whether the snow melted or grew. This was done for a variety of conditions, including reduced $\mathrm{CO}_{2}$ (but not orbital insolation changes), and led to the definition of "glaciation-sensitive" regions.

Figure 2 illustrates results for a case with $200 \mathrm{ppm} \mathrm{CO}_{2}$ (the model control uses a value of $330 \mathrm{ppm}$ ) that matches observed Last Glacial Maximum ice sheets reasonably well over North America and Fenno-Scandinavia, but that overestimates ice extent over Siberia and Tibet. This study concluded that variations in atmospheric $\mathrm{CO}_{2}$ played a major role in determining which regions were classified as "glaciation sensitive". Marshall and Oglesby (1994) showed, however, that because extensive snowmelt occurs, the results of Oglesby (1990) were in this case very sensitive to the specific snow-hydrology formulation involved. 
$1 \mathrm{~m} \mathrm{~N}$ Hem 200ppm Fsn=1.0 winter snow depth (m)

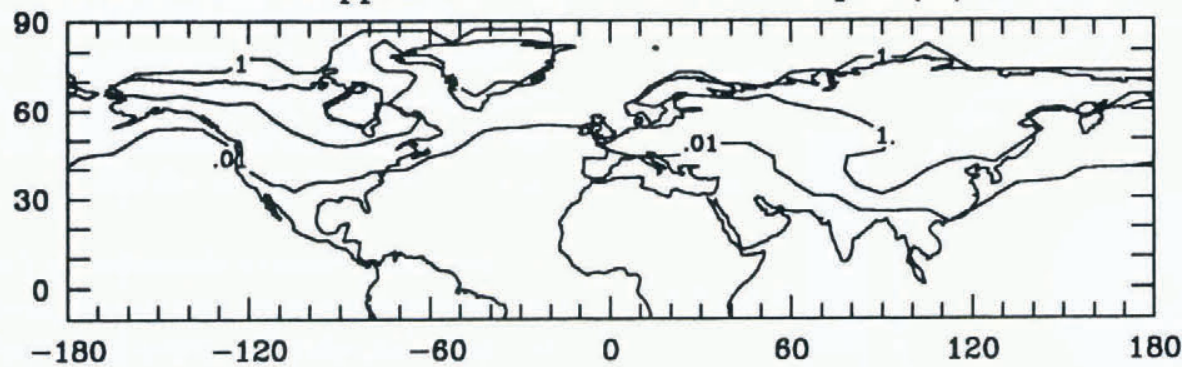

$1 \mathrm{~m} \mathrm{~N}$ Hem 200ppm Fsn=1.0 summer snow depth (m)

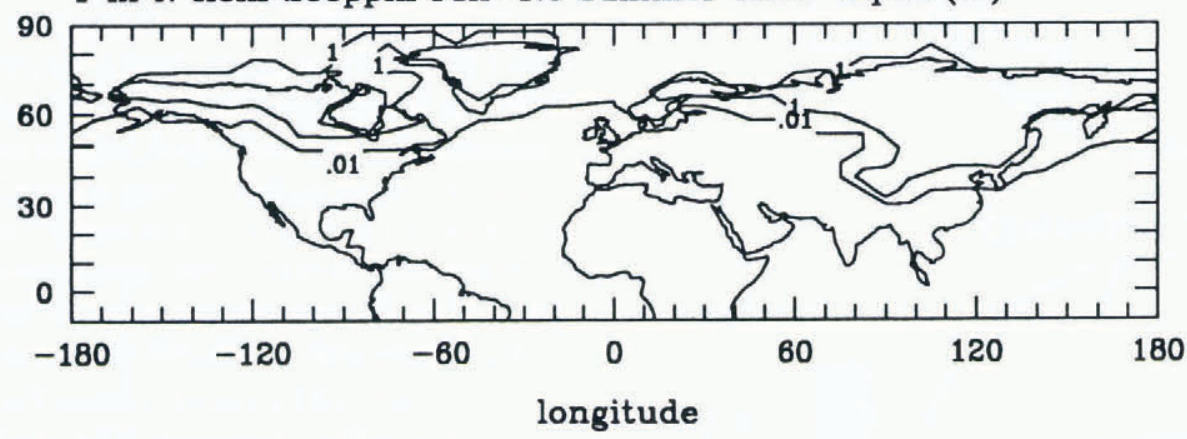

Fig. 2. Snow cover over the Northern Hemisphere in winter after 3 years of a CCM1 run in which $1 \mathrm{~m}$ of snow was initially imposed over all Northern Hemisphere land points, and with $\mathrm{CO}_{2}$ reduced to $200 \mathrm{ppm}$. Contours (in liquid water equivalents) are $0.01 \mathrm{~m}$ (indicating the presence of shallow snow cover), $0.9 \mathrm{~m}$, and $1.1 \mathrm{~m}$ (the latter two indicating where the initial snow cover has been maintained or increased).

Figure 3 shows snow cover over the Northern Hemísphere after a 3 year run starting with $10 \mathrm{~m}$ of initial snow over all Northern Hemisphere land points, using the standard CCM1 "old" snow hydrology as well as the "new" snow hydrology of Marshall and Oglesby (1994). Note that with the new snow hydrology, the area that maintained $10 \mathrm{~m}$ of snow cover is much larger, implying greater ice-sheet volumes than obtained by Verbitsky and Oglesby (1992) (see below). This means ultimately that further improvements in snow hydrology (such as described by Marshall and others, 1997) are necessary to simulate the presence, absence, and volume of ice sheets.
Verbitsky and Oglesby (1992) explicitly simulated Northern Hemisphere glaciation as a function of atmospheric $\mathrm{CO}_{2}$ using results from Oglesby (1990) and Oglesby and Saltzman (1992), in which a series of simulations with CCMl systematically varying atmospheric $\mathrm{CO}_{2}$ from 100 1000 ppm was made. Verbitsky and Oglesby (1992) imposed snow everywhere over the Northern Hemisphere, varied $\mathrm{CO}_{2}$, and then used an ice-sheet model in conjunction with the GCM results to simulate the volume of ice sheets for each of the $\mathrm{CO}_{2}$ values. They found that the volume of ice decreased approximately linearly with increases in $\mathrm{CO}_{2}$, but the volume of ice was an order of magnitude less than
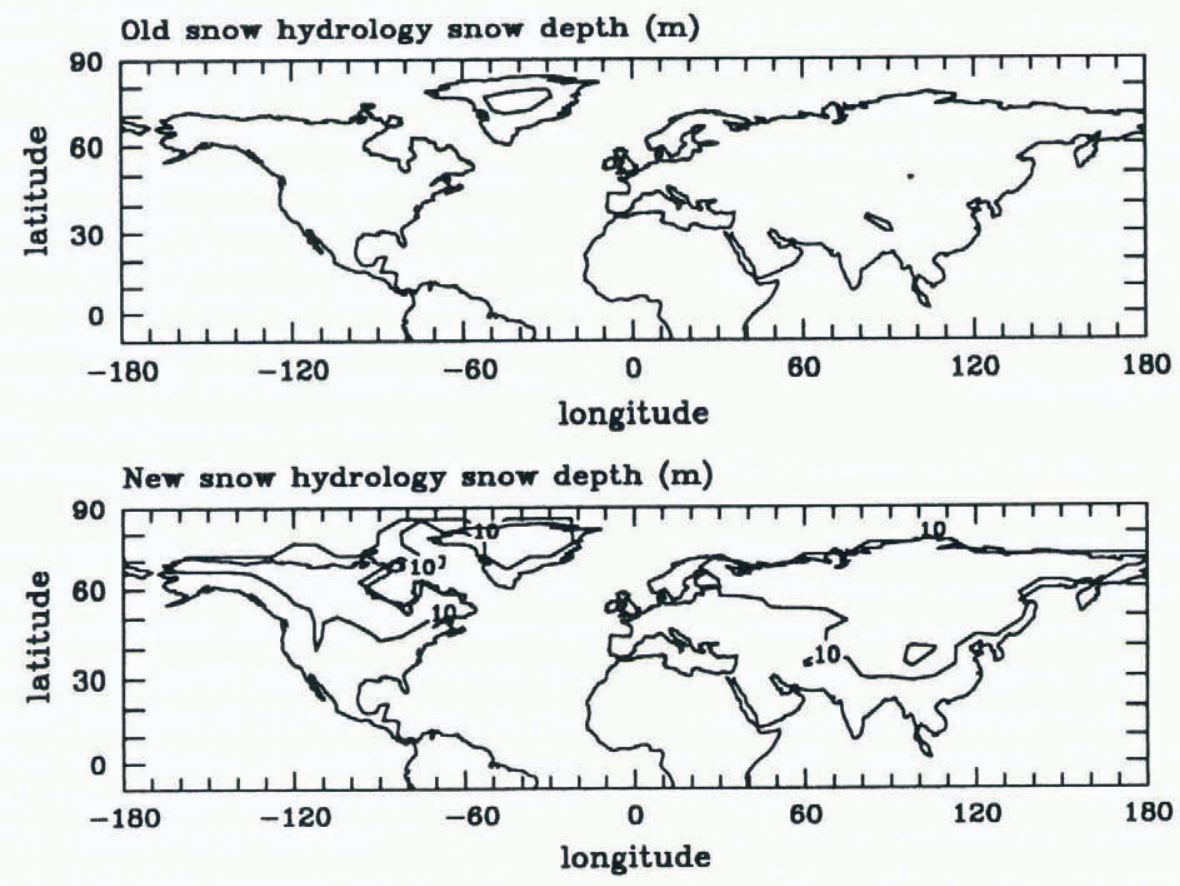

Fig. 3. Snow cover over the Northern Hemisphere after 3 years of a run started with $10 \mathrm{~m}$ of liquid water-equivalent snow cover over all Northern Hemisphere land points. The contour shown is $10 \mathrm{~m}$. 
that reconstructed for actual ice sheets during the late Quaternary. Figure 4 shows ice volume as a function of $\mathrm{CO}_{2}$ for the Northern Hemisphere. Verbitsky and Oglesby (1992) concluded that $\mathrm{CO}_{2}$ was not a primary driver of the Pleistocene ice ages, but that it may have played an important secondary role in determining the volume of ice that occurred.

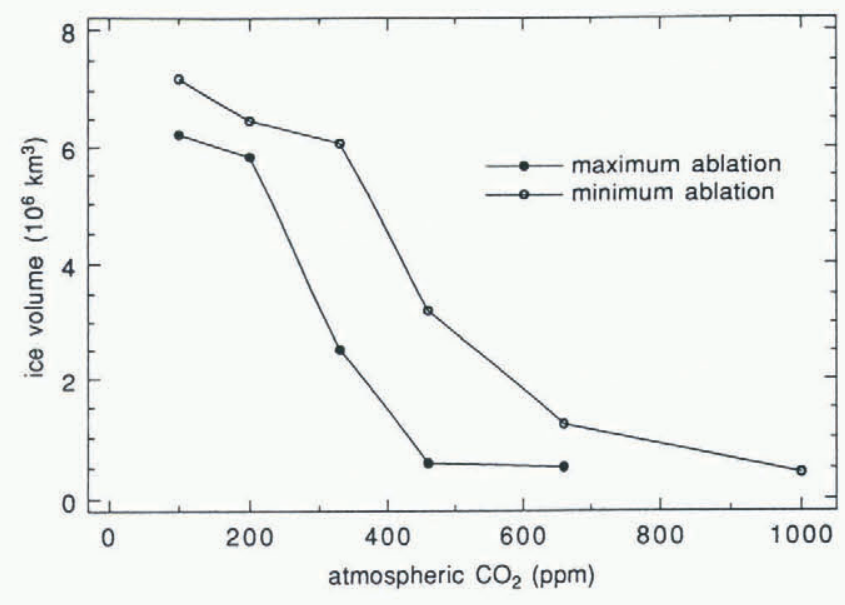

Fig. 4. Northern Hemisphere ice volume (in millions $\mathrm{km}^{3}$ ) as a function of atmospheric $\mathrm{CO}_{2}$ (in ppm) for two slightly different snowmelt formulations, as simulated using the CCMI.

\section{DISGUSSION AND CONCLUSIONS}

\section{Key results and implications}

(1) To first order, the topography and polar position of the continent are most important in explaining the presence or absence of large ice sheets over Antarctica, while SSTs play a more secondary role, acting to modify the extent of glaciation but not its occurrence. Continentality (that is, the size of the continent without regard to geographic or polar position) appears to play a tertiary role at best, meaning, for example, that the attachment of Australia to Antarctica prior to about $40-50 \mathrm{Ma}$ has little effect. Atmospheric $\mathrm{CO}_{2}$ concentration has little impact on the presence or size of the Antarctic ice sheet.

(2) Important conclusions regarding Northern Hemisphere glaciation are that atmospheric $\mathrm{CO}_{2}$ concentration has a significant effect on the location and extent of continental ice sheets, but that the total ice volume involved is small compared to the total amount observed at present or inferred to exist during the Pleistocene ice ages. Furthermore, snow cover as an initial condition plays a role in model-determined glaciation, suggesting the importance of consecutive years of abnormally heavy winter snowfall.

\section{What needs to be done}

All of these previous modeling studies suffer from use of crude models that in many ways are inadequate to the task at hand. Current models suffer from (1) deficiencies in the simulation of the present-day observed climate, affecting the accuracy to which they can compute the large-scale convergence of water vapor; (2) coarse resolution, meaning that topographic features and mesoscale climates cannot adequately be simulated; and (3) simplifications and deficiencies in the treatment of snow physics, especially with regard to snowmelt.

\section{ACKNOWLEDGEMENTS}

This work has been supported by a Department of Energy grant to Purdue University (DOE FG02-85ER60304) and a NOAA grant (NA 66GP0268) to the University of North Carolina-Charlotte.

\section{REFERENCES}

Crowley, T. J., W. J. Hyde and D. A. Short. 1989. Seasonal cycle variations on the supercontinent of Pangea. Geolog), 17 (4),457-460.

Felzer, B. S., T.W. Webb, III and R. J. Oglesby. In press. The impact of ice sheets, $\mathrm{CO}_{2}$, and orbital insolation on Late Quaternary climates: sensitivity experiments with a general circulation model. Quat. Sci. Rev..

Felzer, B. S., R. J. Oglesby, T.W. Webb, III and D. E. Hyman. 1996. Sensitivity of a general circulation model to changes in Northern Hemisphere ice sheets. J. Geophys. Res., 101 (D14), 19,077-19,092.

Marshall, S. and R.J. Oglesby. 1994. An improved snow hydrology for GCMs. Part 1: Snow cover fraction, albedo, grain size, and age. Climate Dyn., $10(1-2), 21-37$.

Marshall, S., A.W. Nolin, R.J. Oglesby and G. T. Bates. 1997. Improving climate model representations of snow hydrology. Ann. Glaciol., 25 (see paper in this volume).

Oglesby, R.J. 1989. A GCM study of Antarctic glaciation. Climate Dyn., 3 (3), $135-156$.

Oglesby, R.J. 1990. Sensitivity of glaciation to initial snow cover, $\mathrm{CO}_{2}$, snow albedo, and oceanic roughness in the NCAR CCM. Climate Dyn., 4(4), 219-235.

Oglesby, R. J. 1991. Joining Australia to Antarctica: GCM implications for the Cenozoic record of Antarctic glaciation. Climate Dyn., 6 (6), 13 22.

Oglesby, R.J. and B. Saltzman. 1992. Equilibrium climate statistics of a GCM as a function of atmospheric $\mathrm{CO}_{2}$ : I. Geographic distribution of primary variables. f. Climate, 5, 66-92.

Rind, D., D. Peteet and G. Kukla. 1989. Can Milankovitch orbital variations initiate the growth of ice sheets in a general circulation model? 7. Geophys. Res., 94 (D10), 12,851-12,871.

Saltzman, B. 1990. Three basic problems of paleoclimate modeling: a personal perspective and review. Climate Dyn., 5 (5), 67-88.

Verbitsky, M.Ya. and R.J. Oglesby. 1992. The effect of atmospheric carbon dioxide concentration on continental glaciation of the Northern Hemisphere. J. Geophys. Res., 97 (D5), 5895-5909.

Verbitsky, M.Ya. and R.J. Oglesby. 1995. The $\mathrm{CO}_{2}$-induced thickening/ thinning of the Greenland and Antarctic ice sheets as simulated by a GCM (CCMl) and an ice-sheet model. Climate Dyn., 11 (9), 247-253. 